\title{
Evaluation of Salt Cavern Closure Via FEM Code PLAXIS
}

\author{
G. Gjerapic Golder Associates Inc., USA \\ T.W. Thompson Golder Associates Inc., USA
}

\begin{abstract}
Determining suitable operating pressures is important when developing deep storage cavities in salt formations due to continuous reduction in the cavern storage capacity caused by creep of the surrounding rock mass. Optimisation for long-term cavern performance typically requires numerical modelling to evaluate different geometries, operating pressures, account for variations in stratigraphy and material properties, and to develop closure predictions over relatively long periods. Commercially available numerical models offer different interface environments and solution methods resulting in varying levels of effort required for model set-up and execution. Models employing a simple graphical user interface and stable fast-execution algorithms are often preferred in the early stages of cavern design.

This paper discusses the implementation and numerical performance of creep algorithms using the finite element model (FEM) code PLAXIS. Constitutive models were implemented to evaluate salt cavern closure at a proposed gas storage facility in southern Arizona, USA. The PLAXIS results were verified against onedimensional analytical solutions and compared to the finite difference code FLAC ${ }^{\mathrm{TM}}$ for a three-dimensional case scenario considering axisymmetric cavern closure.
\end{abstract}

\section{Introduction}

Higher energy costs and environmental advantages over using other fossil fuels, such as coal and oil, are increasing demand for natural gas storage terminals. Most of the existing gas storage in the United States is in depleted natural gas and oil fields. Presently, salt caverns provide only five per cent of the natural gas storage capacity in the United States, in part because their construction is typically more costly than a conversion of depleted gas or oil fields. However, the ability to perform several withdrawal and injection cycles each year is making them more economically attractive as they offer better performance when considering energy supply cycles with rapidly fluctuating demands. In particular, salt caverns provide relatively high withdrawal and injection rates relative to their working gas capacity while requiring a relatively low base (cushion) gas pressure. Consequently, there is an increasing number of projects considering storing natural gas in salt caverns both inland and offshore.

Total gas storage capacity of a salt cavern typically decreases with time due to the continuous cavern deformation resulting from salt creep. Creep relations used to model salt behaviour vary from the simple one-parameter Maxwell model to constitutive models capable of capturing variations in creep rates as a function of stress and temperature. When the laboratory testing supporting model formulation is conducted under the temperature conditions expected in situ, temperature can be ignored, and constitutive models accounting for creep rates as a function of stress are often considered sufficient for modelling the salt behaviour in the field.

Various commercial programs support implementation of user defined constitutive models via dynamic link libraries (DLLs). The choice of a programming language (e.g. C++ and FORTRAN) for constitutive model implementation is typically the modeller's preference. Different commercial programs often vary in applied execution algorithms (solvers). In addition, different programs are likely to vary in the amount of effort required to set up the model. This paper discusses the implementation of viscoelastic creep algorithms in the FEM program PLAXIS (Brinkgreve, 2002) using the user defined dynamic link libraries. The implemented creep models were verified against analytical solutions and compared to results using the finite difference code FLAC ${ }^{\mathrm{TM}}$ (Itasca, 2005) for selected axisymmetric salt cavern closure scenarios. 


\section{Implementation}

Two creep models were chosen for implementation using the FEM code PLAXIS: the Maxwell model and the power law model. Both models utilise visco-elastic formulation with the viscous flow applied only to the deviatoric strains, i.e. volumetric strains are assumed to be purely elastic. In addition, both models can be used in the small strain (Eulerian) and large strain (Lagrangian) formulations. While the Eulerian approach utilises initial (nondeformed) nodal coordinates throughout the calculation process, nodal coordinates are updated at every calculation step in Lagrangian formulation.

\subsection{Maxwell model implementation}

The Maxwell model has a linear relationship between strain rate and stress. As represented in the finite difference code FLAC ${ }^{\text {TM }}$ (Itasca, 2005):

$$
\sigma_{i j}^{d}=\left[\sigma_{i j}^{d 0}\left(1-\frac{G \Delta t}{2 \eta}\right)+2 G \Delta \varepsilon_{i j}^{d}\right] \frac{1}{1+\frac{G \Delta t}{2 \eta}}
$$

where:

$$
\begin{aligned}
G & =\text { shear modulus }(\mathrm{kPa}) . \\
\eta & =\text { viscous constant }(\mathrm{kPa} \mathrm{s}) . \\
\Delta \mathrm{t} & =\text { time increment }(\mathrm{sec}) . \\
\Delta \varepsilon_{i j}^{d} & =\text { change in the deviatoric strain tensor realised during } \Delta \mathrm{t} \text { interval (-). } \\
\sigma_{i j}^{d 0} & =\text { initial deviatoric stress tensor }(\mathrm{kPa}) . \\
\sigma_{i j}^{d} & =\text { final deviatoric stress tensor (at the end of } \Delta \mathrm{t} \text { interval) }(\mathrm{kPa}) .
\end{aligned}
$$

The Maxwell model implementation in PLAXIS is straight forward since the program returns the following information (among other) for the user's DLL implementation: 1) initial stresses at the start of the time step, 2) current time increment, and 3) the current strain increments. The implementation algorithm can be summarised as follows:

1) Find initial values of the deviatoric stress tensor from the initial stresses at the start of the time step:

$$
\sigma_{i j}^{d 0}=\sigma_{i j}^{0}-\sigma_{m 0} \delta_{i j}=\left[\begin{array}{ccc}
\sigma_{11}^{0}-\sigma_{m 0} & \sigma_{12}^{0} & \sigma_{13}^{0} \\
\sigma_{12}^{0} & \sigma_{22}^{0}-\sigma_{m 0} & \sigma_{23}^{0} \\
\sigma_{13}^{0} & \sigma_{23}^{0} & \sigma_{33}^{0}-\sigma_{m 0}
\end{array}\right]
$$

where $\sigma_{\mathrm{m} 0}$ denotes initial mean stress and $\delta_{\mathrm{ij}}$ is the Kronecker delta function.

2) Calculate the change in the deviatoric strain tensor realised during $\Delta t$ interval:

$$
\Delta \varepsilon_{i j}^{d}=\Delta \varepsilon_{i j}-\Delta \varepsilon_{m} \delta_{i j}=\left[\begin{array}{ccc}
\Delta \varepsilon_{11}-\Delta \varepsilon_{m} & \Delta \gamma_{12} / 2 & \Delta \gamma_{13} / 2 \\
\Delta \gamma_{12} / 2 & \Delta \varepsilon_{22}-\Delta \varepsilon_{m} & \Delta \gamma_{23} / 2 \\
\Delta \gamma_{13} / 2 & \Delta \gamma_{23} / 2 & \Delta \varepsilon_{33}-\Delta \varepsilon_{m}
\end{array}\right]
$$

where $\Delta \varepsilon_{\mathrm{m}}$ is calculated as one third of the volumetric strain. Note that the off-diagonal deviatoric strain increments in Equation (3) are calculated using the changes in the engineering strains $\Delta \gamma_{12}, \Delta \gamma_{13}$ and $\Delta \gamma_{23}$ made available to the user's DLL by the PLAXIS program (Brinkgreve, 2002).

3) Calculate deviatoric stress tensor components, $\sigma_{i j}^{d}$, using Equation (1). 
4) Calculate stresses at the end of $\Delta t$ interval as:

$$
\sigma_{i j}=\sigma_{i j}^{d}+\left(\sigma_{m 0}+K \Delta \varepsilon_{m}\right) \delta_{i j},
$$

where K denotes material's bulk modulus.

In addition to the calculated stress increments at the end of the $\Delta t$ interval, the user's DLL needs to provide components of the equivalent stiffness matrix $D_{e}$. One should note that the creep model DLL could be viewed as an implementation of a constitutive model for the continuously yielding material following the formulation introduced by Perzyna (1966). Hence, the stress increment $\Delta \sigma_{i j}$ realised during $\Delta t$ can be expressed in the following form:

$$
\Delta \sigma_{i j}=D_{e}\left(\Delta \varepsilon_{i j}-\Delta \varepsilon_{i j}^{v}\right)
$$

where $\Delta \varepsilon_{i j}^{v}$ denotes viscous strain increments and the elements of the stiffness matrix can be expressed in terms of the elastic constants $\mathrm{K}$ and $\mathrm{G}$ :

$$
D_{e}=\left[\begin{array}{ccc}
K+\frac{4}{3} G & K-\frac{2}{3} G & K-\frac{2}{3} G \\
K-\frac{2}{3} G & K+\frac{4}{3} G & K-\frac{2}{3} G \\
K-\frac{2}{3} G & K-\frac{2}{3} G & K+\frac{4}{3} G
\end{array}\right]
$$

\subsection{Power model implementation}

The creep power model implementation follows the von Mises plasticity approach with the creep rate expressed as a scalar quantity:

$$
\underset{c r}{\&}=A \bar{\sigma}^{n}
$$

where $\bar{\sigma}$ stands for the von Mises stress and $A$ and $n$ are material parameters typically determined from laboratory measurements. Following the formulation adopted in FLAC ${ }^{\mathrm{TM}}$, the stress rate for the creep power model can be expressed as:

$$
\&_{i j}^{d}=2 G\left[\underset{i j}{\&}-\frac{3}{2} \underset{c r}{\&} \frac{\sigma_{i j}^{d}}{\bar{\sigma}}\right]
$$

As in the Maxwell model, the volumetric change for the power model is assumed elastic. Equation (8) expresses the stress change as a function of the current deviatoric stress. Hence, the PLAXIS implementation requires an iterative solution to determine stresses at the end of the calculation time step. Similarly to the Maxwell model, the power model implementation algorithm is based on the approach adopted in FLACTM (Itasca, 2005) and can be summarised as follows:

1) Calculate components of the initial deviatoric stress tensor, $\sigma_{i j}^{d 0}$, and current increments of the deviatoric strain tensor, $\Delta \varepsilon_{i j}^{d}$ (see Equations (2) and (3)).

2) Initialise stresses at the end of the current time interval as $\sigma_{i j, N E W}^{d}=\sigma_{i j}^{d 0}$ and set current iteration counter to zero, i.e. iter $=0$.

3) Start new iteration, iter $=i$ iter +1 , set $\sigma_{i j, O L D}^{d}=\sigma_{i j, N E W}^{d}$, define new values for the average deviatoric stress over the current time interval, $\sigma_{i j}^{d m}$, and find the corresponding values for the von Mises stress, $\bar{\sigma}$, and creep rate $\underset{c r}{\&}$ : 


$$
\sigma_{i j}^{d m}=\frac{1}{2}\left(\sigma_{i j}^{d 0}+\sigma_{i j, O L D}^{d}\right), \bar{\sigma}_{O L D}=\sqrt{\frac{3}{2} \sigma_{i j}^{d m} \sigma_{i j}^{d m}}, \underset{c r}{\&}=A \bar{\sigma}_{O L D}^{n}
$$

4) Calculate stresses at the end of the current time interval from Equation (8):

$$
\sigma_{i j, N E W}^{d}=\sigma_{i j}^{d 0}+2 G\left[\Delta \varepsilon_{i j}^{d}-\frac{3}{2} \&_{c r} \Delta t \frac{\sigma_{i j}^{d m}}{\bar{\sigma}}\right]
$$

5) Determine calculation error as:

$$
\text { error }=\sum_{i=1}^{3} \sum_{j=1}^{3} \frac{\left|\sigma_{i j, N E W}^{d}-\sigma_{i j, O L D}^{d}\right|}{\left|\sigma_{i j}^{d 0}\right|}
$$

6) Check if error < tolerance. If not, repeat steps 3) to 6).

7) Calculate $\sigma_{i j}$ stress tensor at the end of the current time increment as defined by Equation (4), and return components of the equivalent stiffness matrix $D_{e}$ (Equation (6)).

\section{Model validation}

Numerical creep algorithms can be compared to analytical solutions derived for triaxial compression with the axial stress $\sigma_{1}$ and radial stress $\sigma_{3}$. The average axial creep rate for a one-dimensional cylinder with the height $H$ and specific weight $\gamma$ can be expressed as follows for the Maxwell model:

$$
\&_{M, \text { avg }}=\frac{\int_{0}^{H} \varepsilon_{1}(z) d z}{H}=\frac{1}{3 \eta}\left(\sigma_{1}-\sigma_{3}+\frac{\gamma H}{2}\right)
$$

The average axial creep rate for the power model can be written as:

$$
\&_{P, \text { avg }}=\frac{A\left\lfloor\left(\sigma_{1}-\sigma_{3}+\gamma H\right)^{n+1}-\left(\sigma_{1}-\sigma_{3}\right)^{n+1}\right]}{(n+1) \gamma H}
$$

Numerical results from the PLAXIS analyses were validated against the analytical solutions 12 and 13, and compared to the FLAC ${ }^{\mathrm{TM}}$ results. The validation analyses considered a cylinder with the height $H=100 \mathrm{~m}$ and diameter $D=100 \mathrm{~m}$, subjected to the deviator stress of $10 \mathrm{MPa}$. The creep parameters used for these simulations were based on laboratory testing on salt samples from a site in southern Arizona, USA. A summary of creep parameters used in this study is presented in Table 1. A comparison between the measured data and the implemented creep models is illustrated in Figure 1.

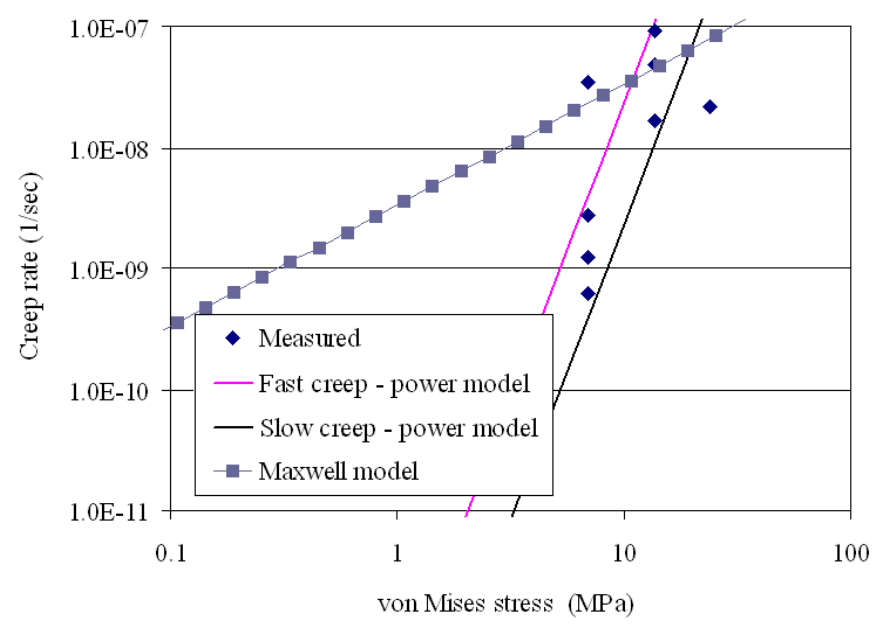

Figure 1 Range of measured creep rates at $80^{\circ} \mathrm{C}$ used for cavern closure modelling 
Parameters describing the Maxwell and power models, for both slow and fast creeping salts, as shown in Figure 1, are summarised in Table 1.

Table 1 Modelling parameters used for numerical validation

\begin{tabular}{ccccc}
\hline $\begin{array}{c}\text { Time Increment } \\
(\mathrm{sec})\end{array}$ & $\begin{array}{c}A_{\text {fast creep }} \\
\left(\mathrm{kPa}^{-\mathrm{n}} \mathrm{s}^{-1}\right)\end{array}$ & $\begin{array}{c}A_{\text {slow creep }} \\
\left(\mathrm{kPa}^{-\mathrm{n}} \mathrm{s}^{-1}\right)\end{array}$ & $\begin{array}{c}n \\
(-)\end{array}$ & $\begin{array}{c}\eta \\
(\mathrm{kPa} \mathrm{s})\end{array}$ \\
\hline $10^{6}$ & $5.87 \times 10^{-28}$ & $5.87 \times 10^{-29}$ & 4.9 & $10^{11}$ \\
\hline
\end{tabular}

PLAXIS implementation of the Maxwell model was tested for Eulerian (small strain) and Lagrangian (large strain) displacement formulations using three vertical stress gradients utilising material densities of one, 10 and $100 \mathrm{kN} / \mathrm{m}^{3}$. The Maxwell model validation results are summarised in Table 2 in terms of axial displacements in metres after $10^{6}$ seconds.

Table 2 Maxwell model - comparison between axial displacements (metres) in triaxial compression

\begin{tabular}{lccc|ccc}
\hline & \multicolumn{3}{c|}{ Eulerian Formulation } & \multicolumn{3}{c}{ Lagrangian Formulation } \\
\cline { 2 - 7 } Model & $\gamma=1 \mathrm{kN} / \mathrm{m}^{3}$ & $\gamma=10 \mathrm{kN} / \mathrm{m}^{3}$ & $\gamma=100 \mathrm{kN} / \mathrm{m}^{3}$ & $\gamma=1 \mathrm{kN} / \mathrm{m}^{3}$ & $\gamma=10 \mathrm{kN} / \mathrm{m}^{3}$ & $\gamma=100 \mathrm{kN} / \mathrm{m}^{3}$ \\
\hline Analytical & 3.35 & 3.50 & 5.00 & 3.29 & 3.44 & 4.84 \\
PLAXIS & 3.45 & 3.59 & 5.10 & 3.09 & 3.19 & 4.50 \\
FLAC & 3.40 & 3.60 & 5.10 & 3.28 & 3.39 & 4.67 \\
\hline
\end{tabular}

A similar validation process was conducted for the PLAXIS power model as summarised in Table 3.

Table 3 Fast creep power model - comparison between axial displacements (metres) in triaxial compression

\begin{tabular}{lccc|ccc}
\hline & \multicolumn{3}{c|}{ Eulerian Formulation } & \multicolumn{3}{c}{ Lagrangian Formulation } \\
\cline { 2 - 7 } Model & $\gamma=1 \mathrm{kN} / \mathrm{m}^{3}$ & $\gamma=10 \mathrm{kN} / \mathrm{m}^{3}$ & $\gamma=100 \mathrm{kN} / \mathrm{m}^{3}$ & $\gamma=1 \mathrm{kN} / \mathrm{m}^{3}$ & $\gamma=10 \mathrm{kN} / \mathrm{m}^{3}$ & $\gamma=100 \mathrm{kN} / \mathrm{m}^{3}$ \\
\hline Analytical & 2.39 & 2.99 & 23.24 & 2.36 & 2.93 & 17.50 \\
PLAXIS & 2.46 & 3.03 & 23.78 & 1.98 & 2.37 & 9.98 \\
FLAC & 2.45 & 3.12 & 23.1 & 2.37 & 2.85 & 12.5 \\
\hline
\end{tabular}

The PLAXIS validation results, which are summarised in Tables 2 and 3, indicate a consistent overprediction of the axial displacements in small strain (Eulerian) simulations and an under-prediction of the calculated axial displacements in large strain (Lagrangian) simulations. PLAXIS predictions exhibit favourable agreement with FLAC ${ }^{\mathrm{TM}}$ calculated values when using the small strain approach. For Lagrangian simulations, i.e. when using continuous updating of mesh coordinates, both FLAC ${ }^{\text {TM }}$ and PLAXIS predictions generally underestimate analytical values. However, Lagrangian simulations conducted by FLAC ${ }^{\mathrm{TM}}$ exhibit a smaller deviation from analytical solutions than observed for PLAXIS analyses.

\section{Numerical evaluation of salt cavern closure}

The implemented creep models were used to evaluate cavern closure. It was assumed that the shape of the cavern is cylindrical with the diameter $D=80 \mathrm{~m}$ and the height $H=190.5 \mathrm{~m}$. Volume loss was calculated as:

$$
\text { Volume loss }=\left(1-\frac{V(t)}{V_{0}}\right) \times 100 \%
$$

where $V(t)$ denotes the cavity volume at time $t$ and $V_{0}$ is the initial cavern volume. Model geometry and material parameters used for the salt cavern closure simulations are summarised in Tables 4 and 5. 
Table 4 Model geometry

\begin{tabular}{llc}
\hline Interval $(\mathrm{m})$ & Layer & Thickness $(\mathrm{m})$ \\
\hline $0-499.8$ & Overburden & 499.8 \\
$499.8-1189.3$ & Top formation mudstone & 689.5 \\
$1189.3-1212.5$ & Anhydrite/mudstone & 23.2 \\
$1212.5-1223.0$ & Upper anhydrite & 10.5 \\
$1223.0-1264.9$ & Roof salt & 41.9 \\
$1264.9-1455.4$ & Cavity salt & 190.5 \\
$1455.4-1466.1$ & Floor salt & 10.7 \\
$1466.1-1767.8$ & Lower anyhydrite & 301.7 \\
\hline
\end{tabular}

Strength and elastic material parameters were determined from laboratory testing and available literature (Goodman, 1980; Handin and Hager, 1957; Hansen et al., 1981; Itasca, 2005; RESPEC, 2004). Elastic and strength parameters used to simulate the cavern closure are shown in Table 5. The primary creep was accounted for by softening the elastic parameters as follows:

$$
\mathrm{E}=\frac{\Delta \sigma_{1}}{\Delta \varepsilon_{1 \mathrm{el}}+\Delta \varepsilon_{1 \mathrm{p}}}
$$

where $\Delta \sigma_{1}$ denotes the change in the axial stress and $\Delta \varepsilon_{1 \mathrm{el}}$ and $\Delta \varepsilon_{1 \mathrm{p}}$ stand for the elastic and primary creep deformations.

The bulk modulus and shear modulus were then defined by using the Poisson's ratio $v=0.45$ as:

$$
\mathrm{K}=\frac{E}{3(1-2 v)}
$$

and

$$
\mathrm{G}=\frac{E}{2(1+v)}
$$

Table 5 Elastic and strength parameters used for cavern closure simulations

\begin{tabular}{clccccc}
\hline $\begin{array}{c}\text { Interval } \\
(\mathrm{m})\end{array}$ & \multicolumn{1}{c}{ Layer } & $\begin{array}{c}\text { Density } \\
\left(\mathrm{t} / \mathrm{m}^{3}\right)\end{array}$ & $\begin{array}{c}\mathrm{K}^{1} \\
(\mathrm{MPa})\end{array}$ & $\begin{array}{c}\mathrm{G}^{1} \\
(\mathrm{MPa})\end{array}$ & $\begin{array}{c}\phi^{1} \\
\left({ }^{\circ}\right)\end{array}$ & $\begin{array}{c}c^{1} \\
(\mathrm{MPa})\end{array}$ \\
\hline Above 1189.3 & Top formation & 2.4 & $2.66 \mathrm{E}+04$ & $2.75 \mathrm{E}+03$ & 15.0 & 1.7 \\
$1189.3-1212.5$ & Anhydrite/mudstone & 2.4 & $1.09 \mathrm{E}+04$ & $3.62 \mathrm{E}+03$ & 29.3 & 10.6 \\
$1212.5-1223.0$ & Upper anhydrite & 2.8 & $2.33 \mathrm{E}+04$ & $1.40 \mathrm{E}+04$ & 45.7 & 12.3 \\
$1223.0-1466.1$ & Salt (softened) ${ }^{2}$ & 2.15 & $2.21 \mathrm{E}+03$ & $2.29 \mathrm{E}+02$ & $\mathrm{n} / \mathrm{a}$ & $\mathrm{n} / \mathrm{a}$ \\
$1466.1-5800.0$ & Lower anhydrite & 2.8 & $1.16 \mathrm{E}+04$ & $6.98 \mathrm{E}+03$ & 27.1 & 14.3 \\
\hline
\end{tabular}

${ }^{1} \mathrm{~K}=$ Bulk modulus, $\mathrm{G}=$ Shear modulus, $\phi=$ Friction angle, $\mathrm{c}=$ Cohesion

${ }^{2}$ Softened bulk and shear moduli to account for both elastic deformation and primary creep.

The range of creep parameters was determined from laboratory testing on salt cylinders with the measured creep rates summarised in Figure 1.

Cavern closure simulations are intended to predict a long-term cavern performance and were therefore run using the average operating pressure applied as a boundary condition along the cavity walls. In order to evaluate the long-term closure of the cavern, an average of the planned maximum and minimum operating 
pressures was used. The average operating pressure chosen for this case was $15.7 \mathrm{MPa}$, approximately $50 \%$ of lithostatic pressure.

Results of the cavern closure simulations are shown in Figures 2 to 4. Similar to the validation test cases summarised in Tables 2 and 3, small strain (Eulerian) simulations yield larger displacements than simulations using the continuous mesh updating approach (Lagrangian). In all cases, small strain solutions obtained by PLAXIS and FLAC ${ }^{\mathrm{TM}}$ exhibit favourable agreement. However, the differences between FLAC $^{\text {TM }}$ and PLAXIS solutions are more significant for Lagrangian simulations and are likely to increase with increasing deformation (Figures 2 to 4). Since both codes use almost identical constitutive models (as illustrated by the comparison between small strain solutions), these differences are most likely due to different algorithms implemented for updating mesh coordinates and different techniques used to calculate the unbalanced force and update tractions at the model boundaries. In particular, the Lagrangian approach poses numerical challenges when accounting for rigid body displacements and rotations reflected in additional "geometric" stiffness in large strain PLAXIS analyses. This phenomenon is not displayed in Eulerian analyses as the nodal movements are governed solely by the implemented constitutive model, i.e. the Eulerian models are not forced to apply compatibility conditions at the end of every time-step since the referent nodal coordinates remain unchanged.

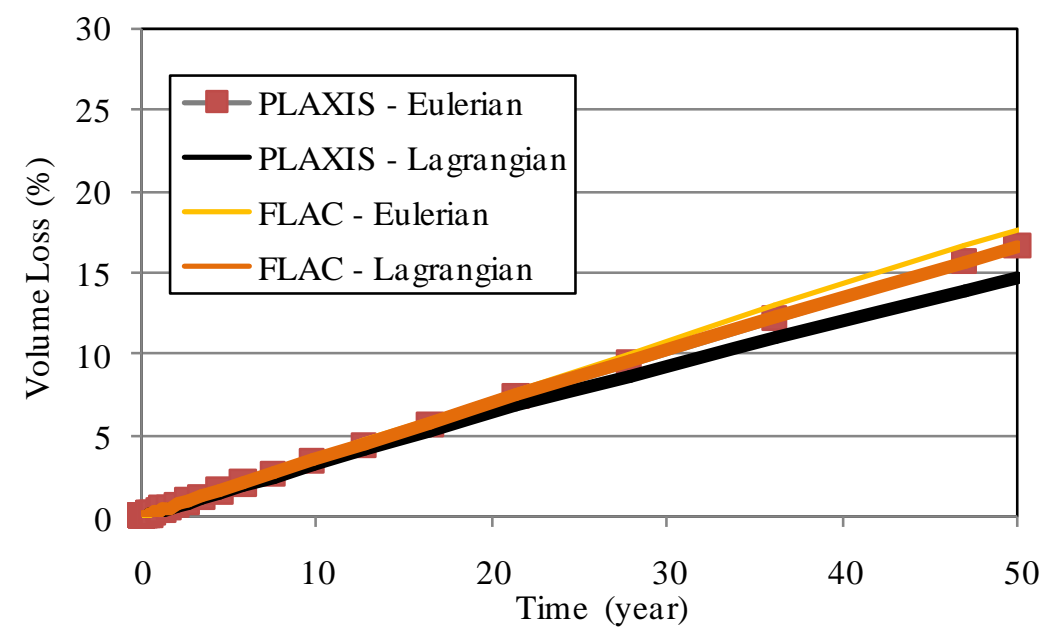

Figure 2 Predicted cavern volume loss - Maxwell model

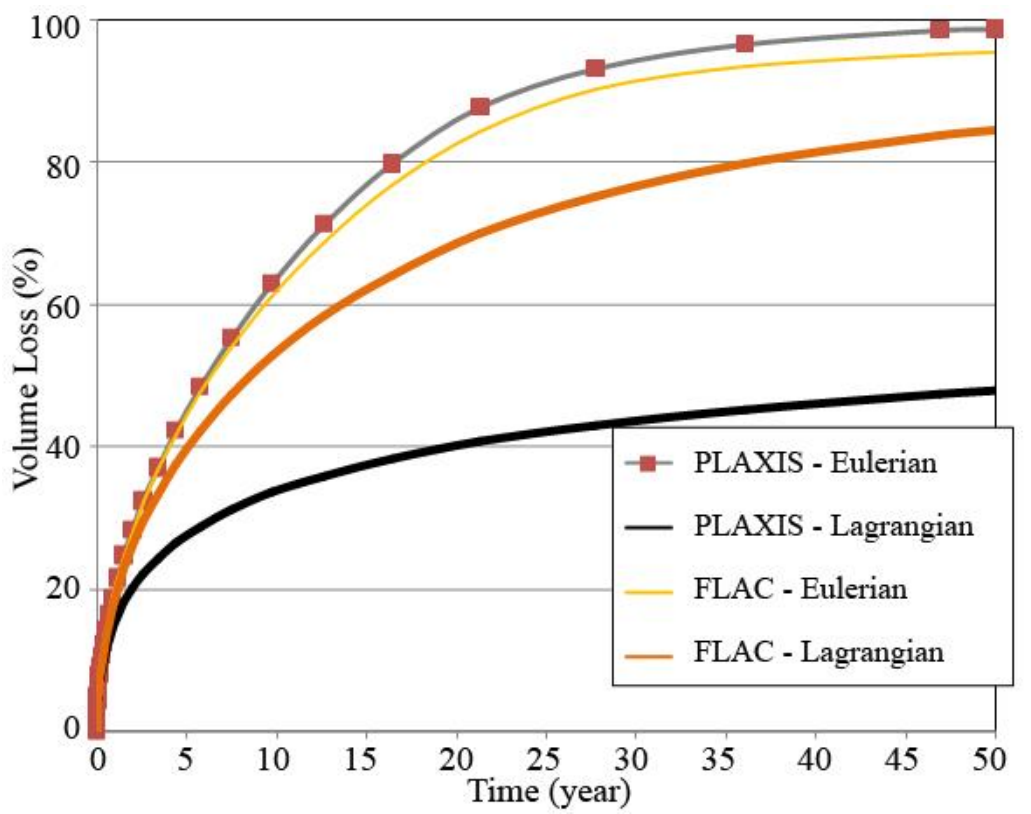

Figure 3 Predicted cavern volume loss for fast creeping salt - power model 


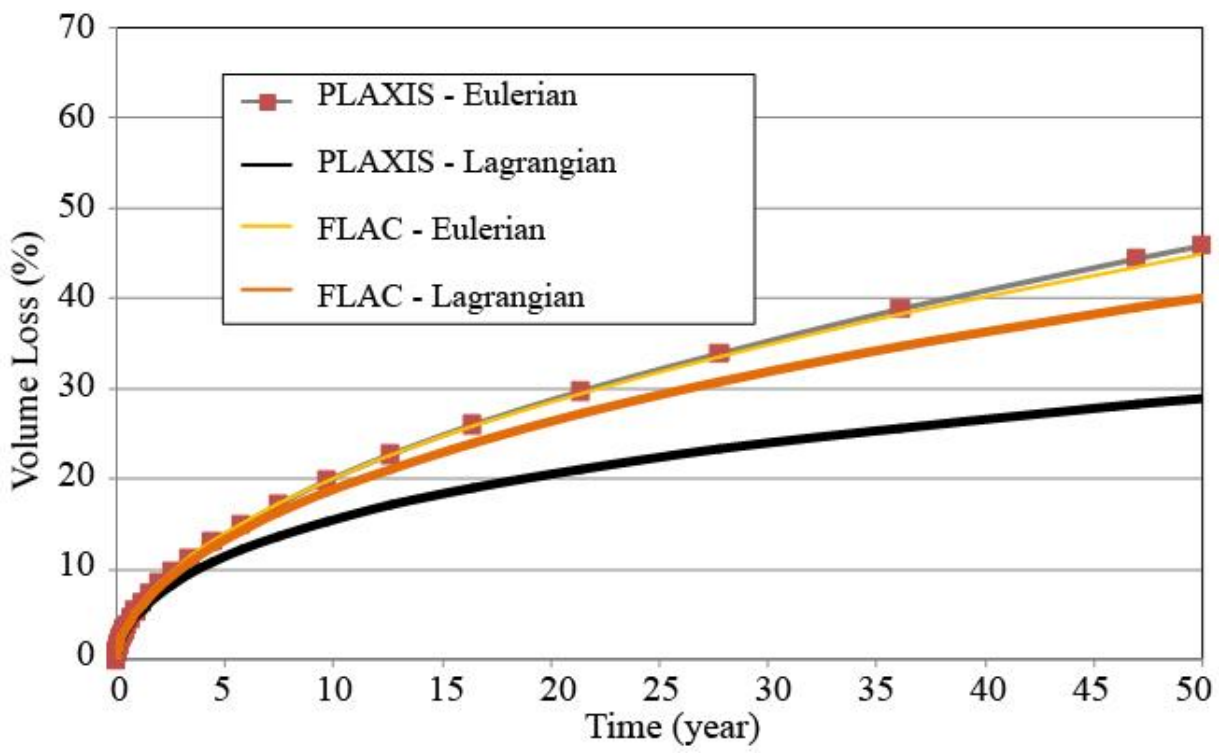

Figure 4 Predicted volume loss for slow creeping salt - power model

As previously noted, PLAXIS and FLAC ${ }^{\mathrm{TM}}$ small strain simulations exhibit relatively close agreement while large strain PLAXIS analyses display smaller displacements than FLACTM resulting in significantly smaller calculated volume loss. Based on the one-dimensional comparison between PLAXIS, FLACTM and analytical results summarised in Tables 2 and 3, FLAC ${ }^{\text {TM }}$ simulations are likely to represent a closer match to exact solution. However, a finite difference formulation implemented in FLAC ${ }^{\mathrm{TM}}$ may yield kinematically inadmissible geometries resulting in over-predictions of the cavern closure.

Figure 5 displays deformations of the finite element mesh in PLAXIS and finite difference grid in FLAC at the upper edge of the cavern at the end of a 50 year simulation for fast creeping salt. In Figure 5, the PLAXIS finite element mesh remains kinematically admissible while the FLAC ${ }^{\text {TM }}$ grid displays elements overlying each other. As the latter case allows for more than one element to occupy the same space, FLACTM simulations at large strains may lead to over-prediction of the cavity volume loss.
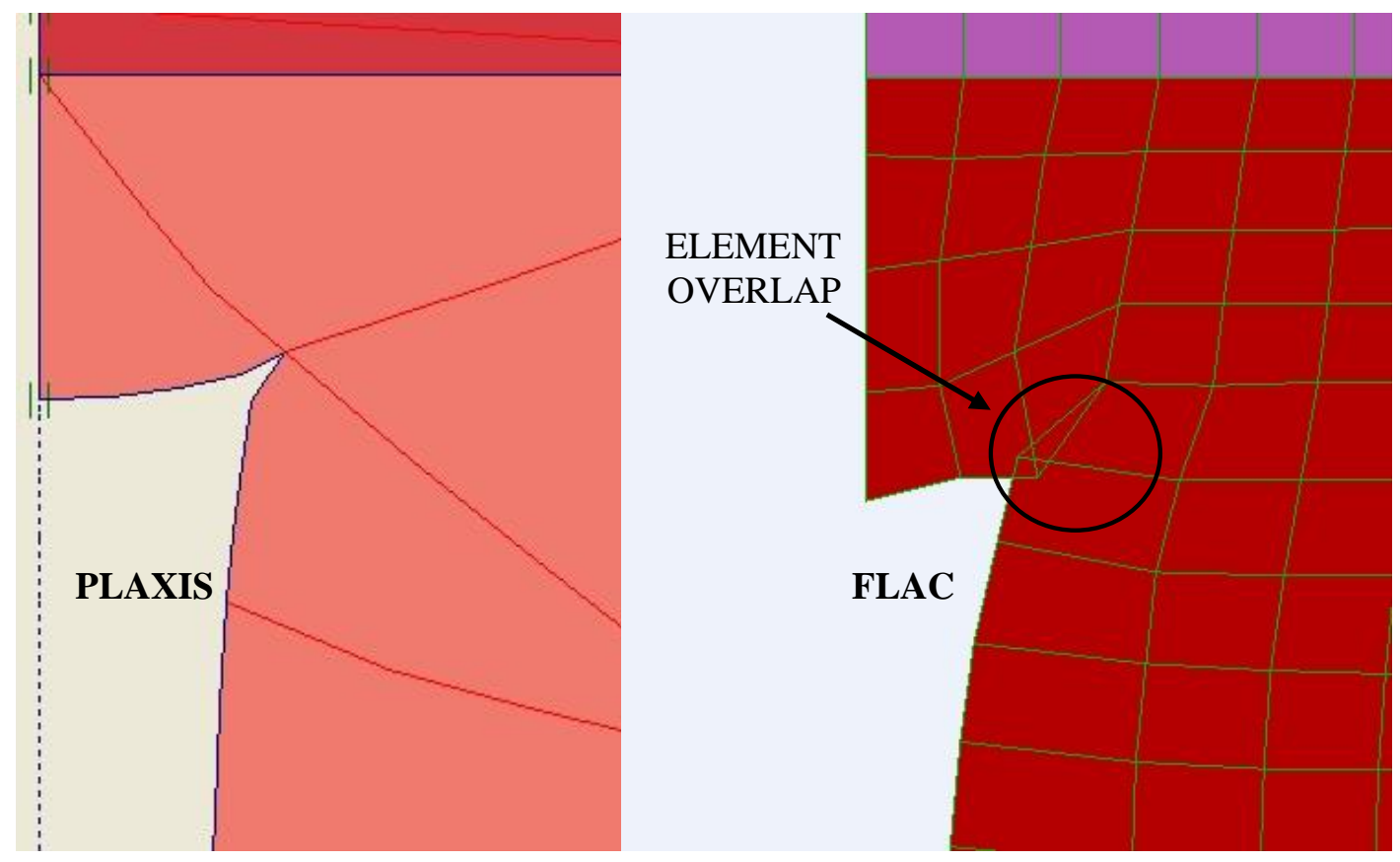

Figure 5 Edge of cavern at the end of simulation for fast creeping salt, PLAXIS versus FLAC 


\section{Conclusions}

This paper presents the finite element implementation of the viscoelastic creep models using the FEM program PLAXIS. The implemented creep formulations utilise generic time-stepping and solution procedures used in the PLAXIS code version 8.0. The implemented creep models can be used for both small strain and large strain calculations. The results from these calculations are likely to present the upper and lower bounds of the true solution. When compared to the finite difference code FLACTM, small strain solutions obtained by PLAXIS are not likely to exhibit significant differences. However, the differences between these two codes are more significant when using the large strain approach (continuous mesh updating) and are likely to become more pronounced as the magnitude of the deformation increases. Large strain results obtained by FLAC ${ }^{\mathrm{TM}}$ are likely to represent a closer match to the exact solution. At large strains, FLAC ${ }^{\text {TM }}$ simulations may result in kinematically inadmissible geometries and over-prediction of the cavern closure.

\section{References}

Brinkgreve, R.B.J. (2002) Plaxis version 8 material models manual, A.A. Balkema Publishers, Netherlands.

Goodman, R.E. (1980) Introduction to rock mechanics, John Wiley and Sons, New York.

Handin, J. and Hager, R.V. Jr. (1957) Experimental study of the strength of sedimentary rocks under confining pressure: tests at room temperature on dry samples, American Association of Petroleum Geologists Bulletin, Vol. 41, No. 1, pp. 1-50.

Hansen, F.D., Kirby, D.M. and Senseny, P.E. (1981) Elasticity and strength of ten natural rock salts, First Conference on the Mechanical Behavior of Salt, Pennsylvania State University, November 9-11.

Itasca Consulting Group, Inc. (2005) FLAC ${ }^{\text {TM }}$ - Fast Lagrangian Analysis of Continua - optional features, user's manual for version 5.0, Minneapolis Minnesota, USA.

Perzyna, P. (1966) Fundamental problems in viscoplasticity, Advances in Applied Mechanics, Vol. 9, Academic, New York, pp. 343-377.

RESPEC (2004) Disposal room calculations with alternative true waste models, Report RSI-1783 prepared for Sandia National Laboratories, June. 
